University of Nebraska - Lincoln

DigitalCommons@University of Nebraska - Lincoln

Low-latitude auroras: the magnetic storm of 14-15 May 1921

S. M. Silverman

E. W. Cliver

Air Force Research Laboratory

Follow this and additional works at: https://digitalcommons.unl.edu/usafresearch

Part of the Aerospace Engineering Commons

Silverman, S. M. and Cliver, E. W., "Low-latitude auroras: the magnetic storm of 14-15 May 1921" (2001). U.S. Air Force Research. 4.

https://digitalcommons.unl.edu/usafresearch/4

This Article is brought to you for free and open access by the U.S. Department of Defense at DigitalCommons@University of Nebraska - Lincoln. It has been accepted for inclusion in U.S. Air Force Research by an authorized administrator of DigitalCommons@University of Nebraska - Lincoln. 


\title{
Low-latitude auroras: the magnetic storm of 14-15 May 1921
}

\author{
S.M. Silverman ${ }^{\mathrm{a}, *}$, E.W. Cliver ${ }^{\mathrm{b}}$ \\ a 18 Ingleside Rd., Lexington, MA 02420, USA \\ ${ }^{\mathrm{b}}$ Space Vehicles Directorate, Air Force Research Laboratory, Hanscom AFB, MA 01731, USA
}

Received 30 November 1999; accepted 28 January 2000

\begin{abstract}
We review solar/geophysical data relating to the great magnetic storm of 14-15 May 1921, with emphasis on observations of the low-latitude visual aurora. From the reports we have gathered for this event, the lowest geomagnetic latitude of definite overhead aurora (coronal form) was $40^{\circ}$ and the lowest geomagnetic latitude from which auroras were observed on the poleward horizon in the northern hemisphere was $30^{\circ}$. For comparison, corresponding overhead/low-latitude values of $48^{\circ} / 32^{\circ}$ and $41^{\circ} / 20^{\circ}$ were reported for the great auroras on 28-29 August and 1-2 September 1859, respectively. However, for the 1921 event, there is a report of aurora from Apia, Samoa, in the southern hemisphere, within $13^{\circ}$ of the geomagnetic equator. This report by professional observers appears to be credible, based on the aurora description and timing, but is puzzling because of the discrepancy with the lowest latitude of observation in the northern hemisphere and the great implied auroral height ( $\sim 2000 \mathrm{~km}$, assuming overhead aurora at Auckland, New Zealand). We discuss various possibilities that might account for this observation. (c) 2001 Published by Elsevier Science Ltd.
\end{abstract}

Keywords: Aurora; Magnetic storm

\section{Introduction}

During intense geomagnetic storms, the auroral oval both expands and moves equatorward, occasionally becoming visible from tropical latitudes. Visual auroras at low latitudes are rare. The associated great magnetic storms serve as extreme test cases for magnetospheric modelers and represent worst case scenarios for space weather forecasters. Thus we are engaged in a review of historical low-latitude aurora in an effort to determine such parameters as their equatorward limits. Only a handful of low-latitude auroras have been reported for the century preceding the IGY, the major ones occurring in 1859(2), 1872, 1909, and 1921 (Chapman, 1957; Botley, 1957; Vallance Jones, 1992; Silverman, 1995). The two events in 1859 , occurring on the nights of 28-29 August and 1-2 September, were analyzed in detail by Loomis (1861) and Kimball (1960). The August event

\footnotetext{
* Corresponding author. Tel.: 1-781-861-0368; fax: 1-781862-1059.

E-mail address: smpr@ma.ultranet.com (S.M. Silverman).
}

was observed within $32^{\circ}$ of the geomagnetic equator, while the famous event in September (associated with the first report of a white light solar flare) was visible from Honolulu at $20^{\circ}$ north geomagnetic latitude.

Can auroras be observed even closer to the geomagnetic equator, as has been occasionally been reported in the literature? Silverman (1995) considered this question for the great storm of 25 September 1909, for which there were reports of aurora at Singapore, $-8^{\circ}$ magnetic latitude. He concluded that no visual aurora was seen in this event for geomagnetic latitudes less than about $30^{\circ}$, and that reports of visual aurora at lower latitudes were due to a confusion of storm effects on telegraph and cable communications (known to be associated with aurora) with visual aurora. Over time, with retelling, such technological effects experienced at Singapore and a few other low-latitudes sites came to be equated with the actual observation of the visual aurora in this event, and were erroneously reported as such in the secondary literature.

During the great magnetic storm of 14-15 May 1921, an apparently credible report of a very low latitude aurora was 
made by Angenheister and Westland (1921, 1922), from the magnetic observatory at Apia, Samoa, geomagnetic latitude, $-13^{\circ}$. They also relayed a report of the aurora from Tongatapu $\left(-23^{\circ}\right.$ geomagnetic latitude). These geomagnetic latitudes are well below the lowest latitude of observation $\left(30^{\circ}\right)$ of the May 1921 aurora by any other observer, and $13^{\circ}$ is one of the lowest magnetic latitudes from which aurora has ever been reported. Are these reports valid? To address this question, we review it in the context of other observations of visual aurora for this event.

The 14-15 May 1921 aurora was observed from Europe, across North America and the Caribbean, and in the Pacific as far west as Australia. From observations in England, Chree (1921) judged the most disturbed period of the magnetic storm to be from 0000 to 0800 GMT (UT) on 15 May, with the subinterval from 0300 to 0730 UT being particularly active. This subinterval corresponds to local times from 2200 (14 May) to 0230 ( 15 May) on the east coast of the United States, 1900-2330 (14 May) on the west coast, and 1300-1730 (15 May) in Melbourne, Australia.

In this paper, all local times are local standard time unless otherwise noted. For each local time, we also give the corresponding UT. For each observing site mentioned, we give the geographic coordinates and the corrected geomagnetic latitude (epoch 1920).

\section{Observations}

\subsection{Solar activity}

The storm occurred on the declining phase of sunspot cycle 15 , some 3.8 years after sunspot maximum. As can be seen in Fig. 1, 1921 was a year of low sunspot activity in a relatively weak solar cycle. May was not particularly active, having a little less than half the average activity of the most active month, July. A period of spotless days, from 4 to 7 May, preceded the period of interest here. The spot group presumably responsible for the storm, Greenwich No. 9334, with a mean area of 1324 millionths of the Sun's visible hemisphere during its disk passage, had a central meridian passage on 14.7 May (preceding data from Royal Greenwich Observatory, 1955, p. 77). The Greenwich Observatory comments (p. 64): "A big complex sport ( $\gamma$ [magnetic class]) unique for its size on the solar equator and of great observational interest because of the distribution of magnetic polarities ... The spot divided into two, resulting in a $\beta \gamma$ group, remnants of which lasted for two months. The geomagnetic storm associated with this spot was a very great one of long duration. Apart from the storm itself, four 'sudden commencements' were recorded". The May 1921 aurora occurred before the establishment of the worldwide flare patrol by Hale during the 1930s (Cliver, 1995) so, to the best of our knowledge, no report of a solar eruption exists for this event.
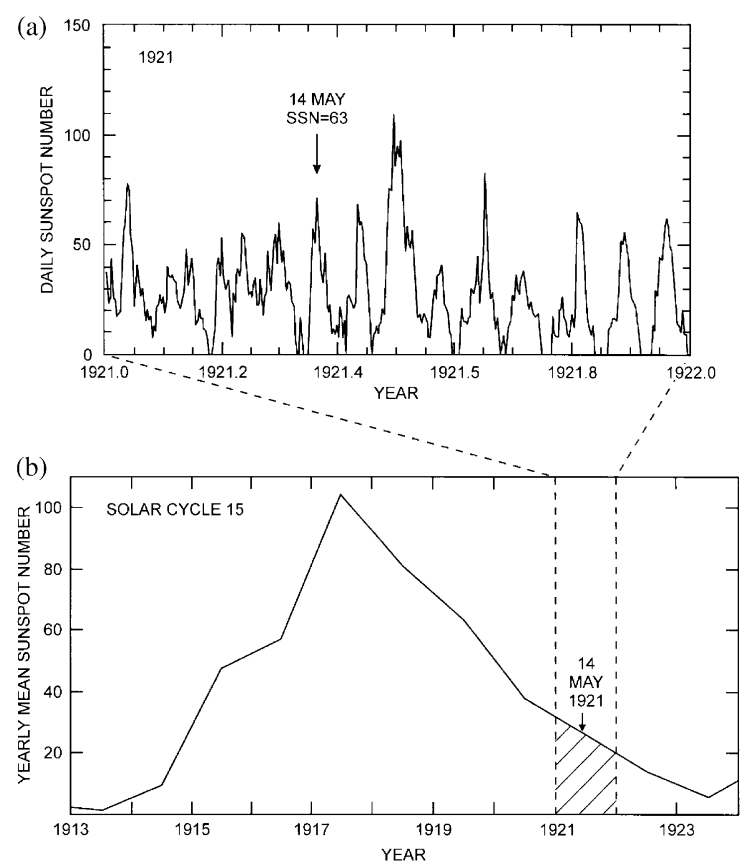

Fig. 1. (a) Daily sunspot numbers during 1921 . The arrow indicates the timing of the 14-15 May magnetic storm. (b) Annual mean sunspot numbers, 1913-1923 (solar cycle 15).

\subsection{The associated magnetic storm}

Annual averages of the geomagnetic $a a$ index (Mayaud, 1973, 1980) during cycle 15 are given in Fig. 2 along with expansions showing daily averages of the $a a$ index for 1921. The geomagnetic storm of 14-15 May dwarfs other activity during that year and was one of the greatest storms of the past $\sim 130$ years. On a listing of the top 50 storms based on daily $a a$ averages for the time interval 1868-1998 (Table 1), 15 May 1921 ranks No. 17. This does not reflect the real ranking, since 14 and 16 May are also on this list (Nos. 36 and 48, respectively), and the sequence of storms taken together makes this period one of the most active in the entire time interval. Also, May 14 (21-24 UT) and 15 (4-6 UT) mark the sixth and seventh highest $3 \mathrm{~h} a \mathrm{a}$ values ever recorded (both at $680 \mathrm{nT}$ ), exceeded only by two values of 715 (13 and 14 March 1989) and three values of 698 (8 July 1958, 15 July 1959, and 4 August 1972). Using another measure, $A A^{*}$ (a modification by Les Morris of a metric proposed by Joe Allen, both of NOAA), the 14 May 1921 storm ranks seventh for the years $1868-1998$. The $A A^{*}$ index is derived by taking 8-point running averages (thus 24 $\mathrm{h}$ ), for $3 \mathrm{~h} a a$ values $>60$, then taking the maximum mean value for a storm interval.

For the month of May 1921 Mayaud (1973) lists a total of seven sudden commencements, all for the period 13-22 May. The greatest disturbance during the 14-15 May storm was signaled by a sudden commencement at 22.2 UT on 14 
(a)

(b)



Fig. 2. (a) $3 \mathrm{~h} \mathrm{aa}$ values during 1921. The arrow indicates the 14 -15 May magnetic storm. (b) Annual mean aa values, 1911-1925.

May; the period of maximum disturbance ranged from the last $3 \mathrm{~h}, 21-24 \mathrm{UT}$, of 14 May to the third $3 \mathrm{~h}, 06-09 \mathrm{UT}$ of 15 May, with activity remaining at a fairly high level until 0900 UT on the 17 th.

More detailed observations of the storm than given in Fig. 2 can be seen in the record of the storm from Apia, Samoa (Angenheister and Westland, 1921) adapted here in Fig. 3. The figure shows the sudden commencement in horizontal intensity at 22.2 UT on the 14th, and the peak disturbance as being at $\sim 0530$ UT on the 15 th. At Kew, the horizontal intensity was off scale from 0300 to 0730 UT; the strongest movements in declination occurred from 0425 to $0525 \mathrm{UT}$; and an abnormally disturbed state of the vertical force lasted from 2200 UT on 14 May to 0800 UT on the 15th (Chree, 1921). Reports from other observatories are consistent with these observations (see Hartnell, 1921; Hazard, 1924; Lemos, 1921; Skey, 1921; Irumata, 1921; Royal Greenwich Observatory, 1955). At several observatories, as at Kew, the excursions were off-scale. At Apia, Samoa, Angenheister and Westland (1921), recognizing that a great magnetic storm was in progress, remained at the observatory throughout the storm in order to manually keep the data from going off the chart. Detailed magnetic data from Apia are available in Westland (1923).

For our purposes the critical times were those near $\sim 0530$ UT on 15 May, at the peak of the storm. Aurora should have been visible where there was darkness near this time, i.e., from the western Atlantic (early morning on the 15th) westward to Australia (early evening on the 15th). The maximum equatorward excursions would be expected near local midnight within this longitudinal range (Feldstein and Starkov, 1967 ), i.e., at longitudes $\sim 68-98^{\circ} \mathrm{W}$, corresponding to the east-central portions of North America, the Caribbean, and western South America.

\subsection{Effects on telegraph, cable and wireless}

Effects of the storm on communications were widespread and severe. In New Zealand (Gibbs, 1921), for example, signals at all radio stations were very erratic, telegraph lines suffered from violent fluctuations of current, and unusual interference was experienced at certain telephone exchanges. Overall the disturbances were of greater magnitude and more far-reaching than had previously been observed in New Zealand.

In the United States telegraph service was affected to an unprecedented extent, such that on the 14th service virtually ended near midnight on lines from the Atlantic Coast to the Mississippi (New York Times, 15 May 1921). In one instance it took an operator nearly an hour and a half to transmit 150 words from Bethlehem, Pennsylvania to the New York Times. Wireless signals from Berlin, Germany and Bordeaux, France, however, were strengthened. The storm was reported to have "blown out fuses, injured electrical apparatus and done other things which had never been caused by any ground and ocean currents known in the past". It was anticipated that ships would have to drag up submarine cables to repair the damage (New York Times, 17 May 1921). The storm was reported to have burned out a telephone station in Sweden, and probably to have contributed to a fire in a New York signal tower. French telegraph lines were also affected, and "seemed possessed by evil spirits". The Central New England Railroad station in Brewster, NY was destroyed by a fire which originated in the telegraph. The telegraph operator said that "he was driven away from his instrument by a flare of flame which enveloped the switchboard and ignited the building". In the western United States telegraph communication was disrupted in Denver, Colorado; Salt Lake City, Utah; San Francisco, California; Seattle and Spokane, Washington; Winnemucca, Nevada; and Helena, Montana. Cable and telegraph lines to Alaska were completely out of commission for a time (Lyman, 1921).

\subsection{The visual aurora}

The series of storms led to observations all over the globe. Observations were compiled from scientific journals, 
Table 1

Magnetic storms, 1868-1998, 50 largest daily aa averages (Data from NOAA)

\begin{tabular}{|c|c|c|c|c|c|c|c|c|c|c|}
\hline 1960 & 1113 & 357 & 355 & 568 & 568 & 357 & 222 & 277 & 113 & 352.1 \\
\hline 1941 & 918 & 7 & 212 & 261 & 408 & 408 & 526 & 526 & 448 & 349.5 \\
\hline 1989 & 313 & 80 & 171 & 363 & 363 & 365 & 284 & 445 & 715 & 348.2 \\
\hline 1959 & 715 & 24 & 37 & 436 & 436 & 355 & 698 & 564 & 223 & 346.6 \\
\hline 1909 & 925 & 7 & 2 & 30 & 410 & 658 & 658 & 658 & 209 & 329.0 \\
\hline 1946 & 328 & 33 & 54 & 448 & 408 & 656 & 526 & 276 & 173 & 321.7 \\
\hline 1903 & 1031 & 30 & 74 & 262 & 337 & 658 & 658 & 286 & 160 & 308.1 \\
\hline 1958 & 78 & 16 & 23 & 302 & 277 & 277 & 698 & 355 & 490 & 304.7 \\
\hline 1882 & 1120 & 262 & 262 & 410 & 536 & 536 & 262 & 107 & 62 & 304.6 \\
\hline 1941 & 75 & 93 & 41 & 448 & 408 & 526 & 468 & 259 & 173 & 302.0 \\
\hline 1960 & 41 & 277 & 355 & 222 & 167 & 355 & 490 & 357 & 167 & 298.7 \\
\hline 1958 & 211 & 568 & 277 & 357 & 485 & 355 & 166 & 78 & 99 & 298.1 \\
\hline 1882 & 417 & 211 & 337 & 456 & 281 & 536 & 334 & 148 & 35 & 292.2 \\
\hline 1928 & 78 & 656 & 331 & 212 & 419 & 259 & 157 & 163 & 30 & 278.3 \\
\hline 1946 & 922 & 22 & 206 & 261 & 656 & 526 & 331 & 103 & 73 & 272.2 \\
\hline 1882 & 1117 & 74 & 74 & 30 & 531 & 262 & 531 & 262 & 337 & 262.6 \\
\hline 1921 & 515 & 346 & 680 & 553 & 185 & 97 & 76 & 43 & 76 & 257.0 \\
\hline 1941 & 31 & 18 & 93 & 206 & 157 & 331 & 656 & 408 & 127 & 249.5 \\
\hline 1986 & 28 & 115 & 115 & 137 & 102 & 228 & 228 & 578 & 445 & 243.5 \\
\hline 1940 & 325 & 526 & 261 & 338 & 261 & 212 & 42 & 124 & 173 & 242.1 \\
\hline 1938 & 122 & 127 & 212 & 538 & 656 & 127 & 157 & 60 & 41 & 239.7 \\
\hline 1872 & 24 & 35 & 15 & 22 & 30 & 158 & 158 & 158 & 262 & 229.7 \\
\hline 1940 & 324 & 90 & 30 & 42 & 42 & 157 & 526 & 448 & 448 & 222.8 \\
\hline 1926 & 1015 & 173 & 157 & 124 & 157 & 157 & 289 & 448 & 276 & 222.6 \\
\hline 1894 & 720 & 22 & 11 & 54 & 262 & 531 & 337 & 262 & 286 & 220.6 \\
\hline 1882 & 1118 & 464 & 464 & 125 & 262 & 126 & 94 & 94 & 126 & 219.3 \\
\hline 1960 & 106 & 99 & 222 & 133 & 167 & 167 & 302 & 302 & 357 & 218.6 \\
\hline 1972 & 85 & 355 & 299 & 222 & 167 & 223 & 223 & 133 & 99 & 215.1 \\
\hline 1991 & 65 & 101 & 137 & 227 & 284 & 227 & 363 & 227 & 136 & 212.8 \\
\hline 1989 & 314 & 715 & 284 & 171 & 59 & 45 & 80 & 171 & 136 & 207.6 \\
\hline 1982 & 96 & 134 & 223 & 223 & 222 & 434 & 222 & 99 & 79 & 204.5 \\
\hline 1960 & 430 & 99 & 78 & 58 & 78 & 277 & 568 & 355 & 99 & 201.5 \\
\hline 1894 & 820 & 42 & 464 & 334 & 456 & 158 & 62 & 30 & 42 & 198.5 \\
\hline 1941 & 919 & 448 & 408 & 261 & 157 & 54 & 60 & 157 & 42 & 198.3 \\
\hline 1915 & 617 & 74 & 125 & 262 & 248 & 209 & 337 & 158 & 158 & 196.3 \\
\hline 1921 & 514 & 97 & 185 & 110 & 77 & 98 & 182 & 130 & 680 & 194.8 \\
\hline 1946 & 325 & 124 & 103 & 93 & 259 & 331 & 261 & 212 & 173 & 194.5 \\
\hline 1949 & 125 & 331 & 206 & 108 & 63 & 93 & 127 & 338 & 276 & 192.7 \\
\hline 1992 & 510 & 59 & 102 & 284 & 228 & 284 & 194 & 227 & 136 & 189.3 \\
\hline 1870 & 1025 & 54 & 94 & 30 & 92 & 337 & 464 & 262 & 179 & 189.0 \\
\hline 1938 & 125 & 33 & 11 & 7 & 52 & 124 & 173 & 656 & 448 & 188.0 \\
\hline 1983 & 25 & 227 & 171 & 137 & 228 & 228 & 137 & 227 & 115 & 183.7 \\
\hline 1946 & 27 & 41 & 11 & 42 & 408 & 261 & 212 & 157 & 338 & 183.7 \\
\hline 1957 & 923 & 223 & 277 & 222 & 187 & 222 & 167 & 113 & 58 & 183.6 \\
\hline 1872 & 1015 & 211 & 262 & 262 & 209 & 105 & 125 & 158 & 126 & 182.2 \\
\hline 1972 & 84 & 79 & 223 & 167 & 31 & 66 & 45 & 134 & 698 & 180.3 \\
\hline 1919 & 811 & 11 & 22 & 281 & 209 & 281 & 456 & 74 & 107 & 180.1 \\
\hline 1921 & 516 & 130 & 163 & 423 & 346 & 217 & 63 & 43 & 56 & 180.1 \\
\hline 1938 & 416 & 11 & 157 & 656 & 206 & 206 & 103 & 41 & 60 & 180.0 \\
\hline 1892 & 213 & 11 & 74 & 125 & 209 & 158 & 262 & 262 & 337 & 179.7 \\
\hline
\end{tabular}

published reports of national agencies, newspapers, and manuscript materials collected by S. Silverman. Previous compilations of reports of the May 1921 aurora were made by Lyman (1921) for the Monthly Weather Review and Berger (1921) and Beer (1922) for the Meteorologische Zeitschrift.
Descriptions: England. From England and, more generally, Europe, the reports of the aurora correspond to the early phase of the storm beginning near midnight on the 14th and continuing through sunrise shortly after 0300 UT in Central Europe. There are no reports of the aurora during the time of magnetic maximum which would have occurred 


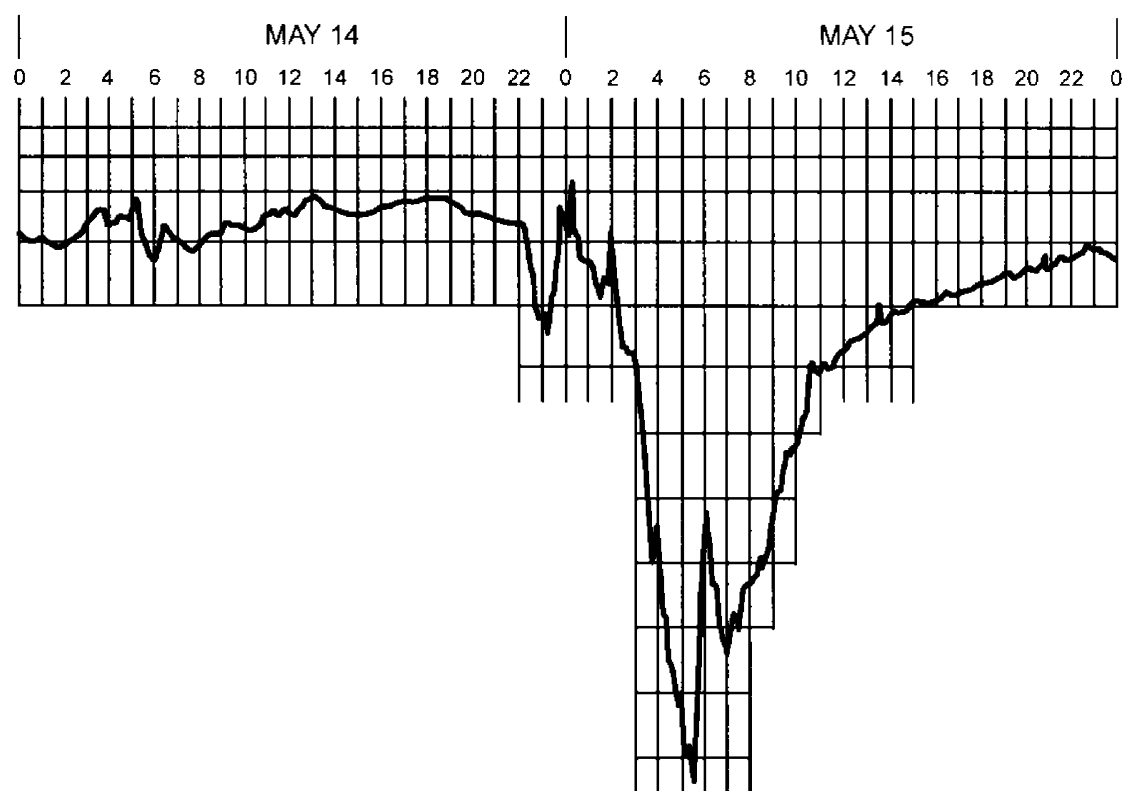

Fig. 3. Record of the horizontal intensity from Apia, Samoa for the great magnetic storm of 14-15 May 1921 (Angenheister and Westland, 1921).

after sunrise in England. Cook (1921) relayed an account of an observation from near Stowmarket (latitude $52^{\circ} 11^{\prime} \mathrm{N}$, longitude $1^{\circ} 0^{\prime} \mathrm{E}$, geomagnetic latitude $\left.50.3^{\circ}\right)$ :

She first noticed the north sky glowing like an immense fire, or distant city lights, about [23] h. G.M.T. At [2345] the light changed to a deep pink and spread from the north point in great bars of pink and violet out to the north-eastern sky, where the colours were the brightest all the time: she compares it to the picture of a vivid sunset when it looks as if the clouds have the appearance of windy weather. From the N.E. it grew paler round towards the N.N.W. The colours were changing every minute, but the two colours seen mostly were green, but not so bright as the shades of pink and violet; at times blue and other colours. At [2330] the Moon was low in the sky, and seemed to have lost all its power. It was at this time the Aurora was at its best; the southern sky was one mass of little white-flecked clouds, which were turned to red by the vivid shape opposite. It was again compared to a wonderful sunset.

Descriptions: North Atlantic. The easternmost description of a corona, an effect of perspective when the aurora is overhead, was reported by H.V. Hansen from the S.S. Eastern Dawn en route from Antwerp to Boston (latitude $41^{\circ} 30^{\prime} \mathrm{N}$, center longitude $48^{\circ} 30^{\prime} \mathrm{W}$, geomagnetic latitude $\left.51.9^{\circ}\right)$ :

Unusual display of Aurora Borealis. Same consisting of streamers coming from all points of the compass and converging toward a common center bearing south and about $80^{\circ}$ altitude. The brightest display occurred at 1220 A.M. (May 15, L.A.T.) [0334 UT; assuming L.A.T. denotes local apparent time] and a second display at 0300 A.M. [0614 UT].

Descriptions: North America (East Coast). Several reports commented on the brightness of the aurora, particularly in view of the moon's brightness - the moon being at quarter phase. In New York (latitude $40^{\circ} 40^{\prime} \mathrm{N}$, longitude $73^{\circ} 58^{\prime} \mathrm{W}$, geomagnetic latitude $54.2^{\circ}$ ) the aurora was sufficiently bright to be seen from Broadway, in the middle of Manhattan. The New York Times (15 May 1921) reported:

Theatregoers on the way home who chanced to look at the sky last night, rubbed their eyes, decided to sign the pledge and then looked up once more. It was still there, the aurora borealis.

Until after midnight crowds stood in Broadway watching the phenomenon. The flashes extended from the north to the zenith, and a bright star overhead was dimmed by rays of flickering light that showed all colors of the rainbow. On either side, to the East and to the West, the effect was like a curtain flapping in the wind. To the north could be seen a glare usually observed only in more Northern regions, a dark cloud-like formation just below the arches. Even the intense lights of the electric signs along Broadway could not dim the brilliance of the flaring skies that appeared to spring from the flashing signs and leap to the bright, fixed star overhead. In less brilliantly 
illuminated parts of the city the dancing streamers of the northern lights resembled the descriptions of polar nights.

From the Asheville, North Carolina (latitude $35^{\circ} 35^{\prime} \mathrm{N}$, longitude $82^{\circ} 35^{\prime} \mathrm{W}$, geomagnetic latitude $48.4^{\circ}$ ) Sunday Citizen (15 May 1921),

The Aurora Borealis ... appeared at 10:10 [0310 UT] last night and from that time until early 1 o'clock [0600 UT] reaching a point of brilliance seldom seen in the spring appearance. The first light appeared in the northeast and gradually approached the zenith. It formed to a certain extent the famed corona, which is a spot of light just south of the zenith toward which the dipping needle points.

Descriptions: the Caribbean. The lowest magnetic latitudes at which the aurora was observed in the northern hemisphere were all in the Caribbean. Several of these accounts are given here.

At about the time of the maximum of the magnetic storm, the U.S.S. B. Neshammy, at $32.4^{\circ}$ geomagnetic latitude, filed the following report with the US Hydrographic Office:

Latitude $18^{\circ} 40^{\prime} \mathrm{N}$ to $19^{\circ} 00^{\prime} \mathrm{N}$. Longitude $65^{\circ} 17^{\prime} \mathrm{W}$ to $65^{\circ} 27^{\prime} \mathrm{W}$. Sunset usual. Brilliant yellow sky to northard. 11:00 p.m. [0321 UT] 14th to 1:00 a.m. [0521 UT] 15th inst. Very bright sky as of twilight. Bright, fiery sky to northard on horizon. Well defined white (symmetrical) lines as Cirrus clouds. Eight in number about $2^{\circ}$ in width. Accredited to Aurora Borealis. Phenomena remained until moonset 12:50 a.m. L.A.T. [0511 UT]

At San Juan, Puerto Rico, near the Neshammy, at longitude $66^{\circ} 10^{\prime} \mathrm{W}$ and $32.0^{\circ}$ geomagnetic latitude, the aurora was seen after midnight on the 14th, and described as follows (Lyman, 1921):

The sky in the north was brightly alight and seemed filled with golden haze. Five great bars of extra brightness, extending from the horizon to the zenith, starting from a common axis, with diverging arcs about equal, extended through the golden haze and gave a wonderful effect.

Chas. Durant, Superintendent of the Point Morant Lighthouse (to the east of Jamaica at latitude $17^{\circ} 55^{\prime} \mathrm{N}$, longitude $76^{\circ} 12^{\prime} \mathrm{W}$, geomagnetic latitude $30.4^{\circ}$ ) reported:

The aurora borealis was seen here on Sunday (15th) morning from 1 to 2 o'clock [0600-0700 UT]. There was a rosy flush in the northern sky and at 1:20 a.m. [0620 UT], the "lances of light" appeared, reaching upward to $50^{\circ}$, and alternately fading and brightening until 2 a.m. [0700 UT], when the aurora faded out.

From Lieut. A.W. Tucker at Sunny Bank, Gordon Town, about 6 miles to the northeast of Kingston, Jamaica (latitude $18^{\circ} 10^{\prime} \mathrm{N}$, longitude $76^{\circ} 35^{\prime} \mathrm{W}$, geomagnetic latitude $30.7^{\circ}$ ):

On Saturday evening, May 14, at 10:40 p.m. [0340 UT], the northern sky was filled to an altitude of $50^{\circ}$ with a ruddy glow, which appeared something like the reflection of a tremendous brush fire, but approximated rather to a crimson color. At the same time shafts of orange light were projected from behind the hills, covering about $60^{\circ}$ of the northern sky, in azimuth, and reaching an altitude of $40^{\circ} \ldots$ At one time 16 shafts were counted over the space of about $60^{\circ}$ in azimuth, and these remained steady for a considerable time.

From A.T. Wood, third officer on the British S.S. Antillian (latitude $22^{\circ} 07^{\prime} \mathrm{N}$, longitude $86^{\circ} 33^{\prime} \mathrm{W}$, geomagnetic latitude $\left.33.2^{\circ}\right)$

9:50 p.m. [0336 UT; assuming local apparent time] observed peculiar color effect in sky in northeast direction from ship. Small portion of sky showed a decidedly reddish-brown color, which lasted about 10 minutes ... From midnight [0546 UT] on the 14th to 2 a.m. [0746 UT] on the 15 th sky to the north and northeast as bright as though dawn was breaking, long streaks of light continually flashing, sometimes from about $20^{\circ}$ altitude to the zenith. The streaks of light were parallel to each other, not radiating from a center. Color of sky in that direction similar to that reported earlier in the evening.

Descriptions: the corona at magnetic latitudes $\sim 50^{\circ}$ in the continental US. Some of the most vivid descriptions of the aurora come from the United States at magnetic latitudes $\sim 50^{\circ}$ where the aurora was overhead and the corona was visible. For example, H. Choate, an observer for the Weather Bureau at Drexel, Nebraska (latitude $40^{\circ} 15^{\prime} \mathrm{N}$, longitude $82^{\circ} 15^{\prime} \mathrm{W}$, geomagnetic latitude $52.2^{\circ}$ ) reports (Lyman, 1921):

At 11:00 p.m. [0500 UT] the heavens appeared like the roof of an immense gold-lined cave with stalactites (curtains) of light shot up from every part of the horizon. One Omaha paper likened the aurora to "a great tent of light that completely covered the city".

From Springfield, Illinois (latitude $39^{\circ} 46^{\prime} \mathrm{N}$, longitude $89^{\circ} 37^{\prime} \mathrm{W}$, geomagnetic latitude $51.9^{\circ}$ ), the corona is described as "a huge dome or canopy over the earth". An observer in Des Moines, Iowa (latitude $41^{\circ} 35^{\prime} \mathrm{N}$, longitude $93^{\circ} 37^{\prime} \mathrm{W}$, geomagnetic latitude $53.2^{\circ}$ ) described the corona as follows: "Pale white, wavering beams of light covered nearly the entire visible sky. ... at a point approximately $10^{\circ}$ south of the zenith, a vast system of pulsating, shifting, and playing shafts of light converged in a quivering mass." An observer in Grand Junction, Colorado latitude $\left(39^{\circ} 03^{\prime} \mathrm{N}\right.$, longitude $108^{\circ} 33^{\prime} \mathrm{W}$, geomagnetic latitude $47.5^{\circ}$ ) was moved to write, "It is believed that it was a most unusual development of the 'northern lights' or aurora borealis, which developed strange green phosphorescencelike 
wreaths, clouds, and odd shapes in the southern sky while the whole northern sky was by turns lavender, purple, red, and light green. It was wonderfully beautiful, weird, and awe inspiring." From Walla Walla, Washington (latitude $46^{\circ} 03^{\prime} \mathrm{N}$, longitude $118^{\circ} 20^{\prime} \mathrm{W}$, geomagnetic latitude $52.7^{\circ}$ ), “. . .the northern lights were said to be hanging over the city much like a large umbrella".

Descriptions: North America (Arizona). Descriptions from this state warrant special mention because they are among the most "professional" accounts given of the aurora and also because they include the lowest latitude accounts of overhead aurora.

Prof. A.E. Douglass (1921) the tree ring expert, made this report from the Steward Observatory in Tucson, Arizona (latitude $32^{\circ} 13^{\prime} \mathrm{N}$, longitude $110^{\circ} 55^{\prime} \mathrm{W}$, geomagnetic latitude $39.7^{\circ}$ ):

A very fine display of the northern lights was observed here on Saturday night, May 14, to daylight Sunday morning. It was first observed at 8:30 p.m. [0330 UT] and was most conspicuous in extremely bright patches here and there in the sky, lasting usually not over a minute, with large arcs crossing the northern horizon. It was slightly cloudy, especially overhead and towards the northeast, but bright patches of aurora could be seen in the west, and here and there groups of fine lines were visible, always having a slant of $60^{\circ}$ from the horizontal, corresponding to the dip of the compass at Tucson.

The colors were a dull white, changing to a greenish tint in the northerly glows, a brilliant pearly luster in the patches and an occasional strong red color over large indefinite areas.

The display appeared to be somewhat less intense at 10:30 p.m. [0530 UT], but shortly afterwards showed renewed activity, especially in long lines extending over large parts of the sky, which was now nearly clear, and all pointing toward a vanishing point about $30^{\circ}$ south of the zenith and a little to the west of the meridian, which is the direction of our lines of magnetic force extending toward the South Pole. This vanishing point was very beautiful and was observed by many people. By 1 o'clock [0800 UT] the display had somewhat diminished, but a later view at 3:30 [1030 UT] showed a perfectly clear sky and the ordinary arcs crossing the northerly horizon with occasional nearly vertical streamers extending upward. This was observed in many other parts of Arizona and far exceeds the recollection of anything of the sort seen here in 40 years.

The event was well observed by the staff of Lowell Observatory in Flagstaff, Arizona (latitude $35^{\circ} 11^{\prime} \mathrm{N}$, longitude $111^{\circ} 39^{\prime} \mathrm{W}$, geomagnetic latitude $42.7^{\circ}$ ) by Russell, Slipher, and Lampland. The eminent astronomer Henry Norris Russell (1921) reported:

The very brilliant auroral display which appeared on May 14 exhibited frequently the phenomenon of streamers diverging from a definite point in the heavens, and it was often possible to locate this radiant, with reference to the stars, with considerable accuracy. ... [Russell determined the position of the radiant to be] $57.3^{\circ}$, azimuth $\mathrm{S}, 15.6^{\circ} \mathrm{W}$. The magnetic dip at Flagstaff is $62^{\circ}$ and the variation $15^{\circ} \mathrm{E}$ so that the radiant was very nearly on the magnetic meridian but about $5^{\circ}$ south of the "magnetic zenith".

The aurora was not only very bright in spite of the light of the half moon, but extended surprisingly far south. About 9 p.m. [0400 UT] several patches were seen low in the south, and at 11 [0600] the whole southern sky was full of streamers and patches of light.

\section{V.M. Slipher (1921) reported,}

The rays ... and the cloud forms were present in all parts of the sky at 11 o'clock [0600 UT]. Some of those in the southern sky attracted my attention particularly by undergoing striking fluctuations in brightness.

From C.O. Lampland (1921):

The auroral light was first recognized about 08:25 [0335 UT], or a little earlier, before twilight had disappeared. The lower sky was brilliant in the north and particularly in the northeast, and the characteristic greenish auroral color was predominant but over parts of the active areas a suffused ruddy glow was conspicuous, especially to the northeast. Almost immediately streamers made their appearance in the north and northeast. Ten or 15 minutes later the display developed into great activity. Long brilliant streamers were reaching up towards the zenith and beyond, and at the same time appeared in various parts of the sky, but especially in the east and west, brilliant patches, and masses of light... The greatest activity of the second outburst occurred between the hours of 10 and 11 [0500-0600 UT]. Auroral formations were at that time visible in practically all parts of the sky.... From the time the auroral light was first made out in the waning twilight it was strong, with greatly increased intensity during the intervals of the outbursts mentioned, until after 1 o'clock [0800 UT] when it rapidly subsided into a feeble glow along the northern horizon. It was reported by someone stationed at a sheep camp north of San Francisco Peaks that another outburst of streamers developed later in the night.

Descriptions: Mexico. From Sinaloa, Mexico, at approximately the same longitude as the cited observers in Arizona (latitude $25^{\circ} 15^{\prime} \mathrm{N}$, longitude $107^{\circ} 45^{\prime}$; magnetic latitude $32.6^{\circ}$ ), Lindley (1921) reported:

The Northern light display of May 14 was very plainly visible from the mesa here - only a few miles from the tropics. The Indians have been firing the forests to hasten the advent of the summer rains, and, when I 
first observed the glow along the sky-line formed by the Sierra Madre I thought they were indulging their propitiation of the gods on a rather larger scale than usual. The glow began about 8 o'clock [0300 UT] and the rays were first visible about fifteen minutes later. They were white to pale yellow in color, ever changing in form, location, and brightness. Many of them appeared to reach an east-and-west great circle through the zenith, those low down in the eastern sky appearing longer. The apparent focus was several degrees east of north.

Descriptions: United States (West Coast). From the San Francisco Examiner (15 May 1921):

The aurora borealis, lights of various colors in the sky, common in the north but seldom seen as far south as San Francisco, startled many last night with what looked like a "shimmy of colors" in the heavens. As far south as the Mexican border, electrical discharges in the sky were plainly visible, the first time in history, according to old time residents. Sante Fe train dispatchers say the lights were also clearly seen on the Mojave desert, nearly all points reporting having witnessed them for the first time within the records of the various weather offices.

Descriptions: Northern Pacific. In the northern Pacific, near the time of the maximum excursion of the magnetic field, Captain E. Petterson of the S.S. Hyades, sailing from Bellingham to Honolulu, at latitude $33^{\circ} 18^{\prime} \mathrm{N}$, longitude $146^{\circ} 44 \mathrm{~W}$, geomagnetic latitude $34.6^{\circ}$, at 8:00 p.m. [0547 UT] local apparent time, described the aurora:

On this particular evening observed numerous bright streaks resembling Aurora Borealis in a north and south direction covering about two-thirds of the heavens and giving the northern portion of the sky a peculiar reddish tint.

During this time the sky was very clear excepting the northern part close to the horizon.

9:15 PM [0702 UT] the streaks disappeared leaving the north and eastern part of the sky very red for about fifteen minutes then gradually getting fainter until ten forty-five PM [0832 UT] when it completely disappeared.

Descriptions: New Zealand. At Auckland, New Zealand (latitude $36^{\circ} 51^{\prime} \mathrm{S}$, longitude $176^{\circ} 46^{\prime} \mathrm{E}$, geomagnetic latitude $40.5^{\circ} \mathrm{S}$ ), near the time of maximum magnetic excursion, the aurora was brilliant (New Zealand Herald, 16 May 1921):

A vivid and unusually beautiful display of the Aurora Australis, the southern equivalent of the Aurora Borealis, was to be seen in the southern sky just after dusk last evening. The display ... was not only notable for manifesting itself in such a latitude as that of Auckland, but was of a richness of tinting and distinctness far beyond anything usually to be seen save very much nearer the polar regions. Commencing about $6 \mathrm{pm}$. [0600 UT] it lasted with varying degrees of brilliancy until after 8 o'clock [0800 UT].

During the most brilliant moments, the whole southern sky was suffused with a deep pink coloring, resembling the afterglow of an unusually gorgeous sunset, the pink, varying in places and at moments towards a rich crimson, was shot with broad bands of iridescent light, paling and deepening, changing from light yellowish white to a deep red, and passing through a purple phase in the process. At the periods of maximum brilliancy the auroral rays converged toward two nuclei, one on the south-eastern and the other on the south-western horizon. At the nuclei the glow of rays faded away to patches of sky, olive-green in colour and illuminated with an unusual glow. There were times when the bands of changing colour extended from horizon to zenith over one half of the sky.

A later passage in the same article captures the aurora's effect on the Aucklanders,

As soon as people began to notice the glow in the sky last evening, they commenced crowding out of doors to watch and exclaim. Neighbour called to neighbour to know where the fire was. Then as the rays began to define themselves, and the fire theory became untenable, conjectures ranged from the possibility of an eruption somewhere to that of the impending end of the world. All along the streets people could be seen gazing skyward, while verandahs and balconies all carried their quota, watching and speculating over the unusual appearance in the heavens. Even tram-travellers could not remain indifferent, but crowded to the windows to gaze as the car travelled.

The Auckland Star (16 May 1921) gave a detailed account of the colors of the aurora:

On the horizon there was a band of the most beautiful apple-green against which the trees, buildings, and church spires of the high parts of the city towards the south and south-west were silhouetted as though carved in ebony. Above this the rose-pink in the sky swept upwards in a vast flame, and in places turned to sunset-red and crimson-lake. Diverging from points in the south-east and south-west great shafts of whitish light shot through this glorious sky. And in their passage through the colors they seemed to take on iridescent tints. The most remarkable feature about the display was the rapid and subtle changes through which the bands and patches of colour passed.

At Whangarei, New Zealand (latitude $35^{\circ} 43^{\prime} \mathrm{S}$, longitude $174^{\circ} 19^{\prime} \mathrm{E}$, geomagnetic latitude $39.7^{\circ} \mathrm{S}$ ), the most equatorward site from which the aurora was reported in the southern hemisphere, other than in the report of 
Angenheister and Westland (1921), the description given was (The Northern Advocate, 16 May 1921):

For a couple of hours last night, as observable from Whangarei, a unique manifestation of the Aurora Australis appeared in cloudland over an extensive range approximately from south to west. ... there was an almost stationary background of red with perpendicular white rays lying athwart, presenting a spectacle of rich magnificance which none remember to have been equalled from this district's viewpoint, and generally conceded to have been of a distinctiveness beyond anything usually seen except in regions nearer to and in Polar zones.

The display was widely observed throughout New Zealand and in the southern parts of Australia. One interesting negative report came from the passengers and crew of a steamer "Riverina", traveling from Sydney to Auckland (New Zealand Herald, 17 May 1921). At the time of the strong display at Auckland the steamer was from 60 to 80 miles from Cape Maria Van Diemen off the northern tip of New Zealand (latitude $34^{\circ} 29^{\prime} \mathrm{S}$, longitude $172^{\circ} 39^{\prime} \mathrm{E}$, geomagnetic latitude 39.1S):

The night was not unfavorable for observing anything unusual in the heavens, but nothing was noticed by either passengers or crew. On arrival at Auckland, considerable surprise was expressed at the news of the brilliant display of the previous evening.

Descriptions: Samoa. The data come from Angenheister and Westland (1921), at the Magnetic Observatory at Apia, Samoa (latitude $13^{\circ} 48^{\prime} \mathrm{S}$, longitude $171^{\circ} 45^{\prime} \mathrm{W}$ geographic, $13.1^{\circ} \mathrm{S}$ geomagnetic). Their description reads:

On May 15d. 5-3/4h.-6-1/2h., Greenwich (6.15-7 p.m., May 14, local mean time), a display of the aurora Australis was observed at this Observatory. There is a range of mountains from $600-700 \mathrm{~m}$. high to the south, distant about $10 \mathrm{~km}$; and above this the light could be seen in the form of a segment of a circle, and reaching to an altitude of $22^{\circ}$ determined from star positions noted. It covered probably an arc of about $25^{\circ}$ along the horizon, and the centre was apparently close to the magnetic meridian. In spite of the moonlight (first quarter), and a little twilight as well, the light was very conspicuous and of a glowing red colour. The point of the greatest intensity appeared to move from east to west at about $6 \mathrm{~h} .20 \mathrm{~m}$. Greenwich time, and traces of a brighter yellow coloured streamer were noticed at the same time. The sky was quite free from cloud at this hour; later on some small fracto-cumulus were experienced, but no cirrus clouds were seen. No signs of the light were seen after 7 p.m.

Elsewhere Westland (1921) gives another description:

... I had ... the remarkable experience of viewing the brilliant Aurora Australis of 15 May. This happened within 14 degrees of the equator and with the handicap of bright tropical moonshine from a first quarter moon high overhead. Surely this is a unique observation?

The display was not altogether unexpected, as we were then in the midst of a big geomagnetic storm, and we actually stood by our instruments all night, so as to keep the point of light from running off the bromide paper.

Here the magnitude of the arch was $22^{\circ}$, determined from stars noted at the time, and this in latitude $13^{\circ} 48^{\prime}$. At other islands farther south the observed altitude was greater, but the display was still in the south. Not until Auckland, in latitude $36^{\circ} 50^{\prime}$, is taken into account do the reports state that the light reached to the zenith. Now if we compute the actual height of the light from these data, the result is more than $2000 \mathrm{~km}$, which is simply impossible. Yet, what is the fallacy? It may be that we in Samoa and our fellowmen in New Zealand were not looking at the same thing. But in that case we raise the question of what the physical nature of the aurora may be, which makes the problem all the more difficult.

Angenheister and Westland (1921) (cf., Westland, 1921) report that the aurora was seen from Tongatapu, latitude $21^{\circ} 10^{\prime} \mathrm{S}$, longitude $175^{\circ} 10^{\prime} \mathrm{W}$ (geomagnetic latitude $23.2^{\circ} \mathrm{S}$ ) to the south of Samoa. During the $1950 \mathrm{~s}$ Chapman (1957) made an unsuccessful attempt to obtain further information about the observation from Tongatapu.

Descriptions: Australia. In Melbourne (latitude $37^{\circ} 45^{\prime} \mathrm{S}$, longitude $144^{\circ} 58^{\prime} \mathrm{E}$, geomagnetic latitude $46.1^{\circ} \mathrm{S}$ ), the Aurora Australis was visible from "about half-past 6 to half-past 9 o'clock" [0830-1130 UT] on the night of Sunday, 15 May (The Argus, 17 May 1921), after the peak of the magnetic storm. There were also reports of aurora from central (Israelite Bay; latitude $33^{\circ} 38^{\prime} \mathrm{S}$, longitude $123^{\circ} 55^{\prime} \mathrm{E}$, geomagnetic latitude $43.5^{\circ} \mathrm{S}$ ) and western Australia (Perth; latitude $31^{\circ} 58^{\prime} \mathrm{S}$, longitude $115^{\circ} 49^{\prime} \mathrm{E}$, geomagnetic latitude $41.3^{\circ} \mathrm{S}$, where the aurora was described as being "faintly perceptible" (Kalgoorlie Miner, 21 May 1921)).

Attempts to confirm the low-latitude observation from Apia, Samoa: In an attempt to corroborate the observation of Angenheister and Westland (1921), we searched for newspaper accounts of the aurora from Fiji (longitude $18^{\circ} 00^{\prime} \mathrm{S}$, $178^{\circ} 00^{\prime} \mathrm{E}$, magnetic latitude $21.3 \mathrm{~S}$ ) located between Samoa and Tongatapu in latitude and approximately $10^{\circ}$ west of Tongatapu. The Fiji Times and Herald for 17 May 1921 notes the aurora as having been seen in Australia and New Zealand, as well as disturbances to telegraph and cable services, but does not mention any observation of aurora at Fiji. Similarly the Fiji Times and Suva Times (17 May 1921) carries a report on the magnetic storm effects in Australia, as the "greatest on record", and notes the magnetic disturbances all over the world, but does not mention any report of visual aurora in the nearby islands.

We also searched for an account of the aurora in Hawaii. If the aurora was visible from Samoa, then one would expect 
to find observations from Honolulu (latitude $21^{\circ} 19^{\prime} \mathrm{N}$, longitude $157^{\circ} 48^{\prime} \mathrm{W}$, geomagnetic latitude $22.0^{\circ} \mathrm{S}$ ), which lies roughly along the same magnetic meridian as Samoa in the northern hemisphere but further from the magnetic equator $\left(+22^{\circ}\right.$ for Honolulu vs. $-13^{\circ}$ for Apia). A search of the Honolulu newspapers for the period uncovered no report of aurora observed in Hawaii. The Honolulu Star-Bulletin of 16 May 1921 carries a front page article on the aurora and its effects in the United States, but no mention of aurora seen from Hawaii. The same newspaper (19 May 1921) subsequently gave the full report of the auroral observation from the S.S. Hyades. We checked the Weather Bureau records for Honolulu for 14 May 1921 (National Climatic Data Center, Asheville, North Carolina). The skies were partly cloudy with coverage of $40 \%$, and the monthly summary, under the heading "aurora" simply stated "none".

The null reports from newspapers noted above must be treated with caution. Generally speaking, absence of evidence is not evidence of absence. Even for ideal observing conditions (clear night skies, no moon, no city lights, unobstructed horizon), subtle features may escape notice and even if noticed may go unreported in the local newspapers or elsewhere. Where, however, no notice of local aurora is given even though the paper carries reports of the phenomenon elsewhere, as at Fiji and Honolulu, some evidentiary weight can be given to the indicated absence of aurora.

We also searched for accounts of the aurora in South American papers archived in the Harvard College Library without success. No reports were found of the May 1921 aurora or its effects, except for the La Prensa newspaper from Buenos Aires (16 and 17 May 1921) which, in a special report from London, mentioned the magnetic storm and difficulties with telegraph traffic between the United States and Europe but made no mention of any local observation of aurora.

Call for help: Our search for observations of the 14-15 May 1921 event leaves us convinced that valuable reports of these event remain to be uncovered. Therefore, we encourage readers of this article, particularly those residing at magnetic latitudes below about $45^{\circ}$, to check accounts from their local newspapers for this period and to send them to us so that we might obtain as complete an account of this event as is possible, 80 years after the fact.

\section{Summary of the low-latitude observations of visual aurora on 14--15 May 1921}

\subsection{Overhead aurora (corona)}

The lowest latitude reports of an unambiguous corona for this event are those from Lowell Observatory in Flagstaff Arizona at a magnetic latitude of $42.7^{\circ} \mathrm{N}$, although from Douglass' description at Tucson (magnetic latitude $39.7^{\circ} \mathrm{N}$ ), it seems clear that he observed it there as well. In the southern hemisphere, the many reports from New Zealand consistently refer to the aurora as being to the south. Even at Auckland $\left(40.5^{\circ} \mathrm{S}\right.$ magnetic latitude), at the peak of the auroral display, the description "There were times when bands of changing color extended from horizon to zenith over one half of the sky" suggests a rather short-lived occurrence of something short of corona, which would have had apex $\sim 30^{\circ}$ north of overhead at the magnetic zenith. We attribute more poleward location of the aurora over New Zealand (compared to Tuscon) to the fact that the New Zealand meridian was far from local midnight at the time of the $\sim 0530$ UT peak time of the storm. For less intense magnetic storms, the southernmost extent of the aurora at local times $\sim 1800$ (comparable to that of Auckland for this event) lie several degrees poleward of the most equatorward excursion at midnight (Feldstein and Starkov, 1967).

The observation from the Hyades at 0547 UT in the northern Pacific (magnetic latitude $34.5^{\circ} \mathrm{N}$ ) suggests that corona might have been seen below $40^{\circ}$ magnetic latitude, but the somewhat vague description ("... numerous bright streaks resembling Aurora Borealis north and south direction covering about two-thirds of the heavens and giving the northern portion of the sky a peculiar reddish tint"), the approximate $4 \mathrm{~h}$ offset of the Hyades position from midnight, and the lack of confirming reports do not inspire confidence that it was. Moreover, a linear extrapolation of the relationship between $K p$ and the geomagnetic latitude of auroral equatorward boundaries near midnight given in Whalen et al. (1985) to $K p$ values of 9 gives a low-latitude boundary of only about $47^{\circ}$, well above $34.6^{\circ}$ (but also, of course, above the $39.7^{\circ}$ latitude Tucson where coronal aurora was apparently observed for this event). For the great March 1989 geomagnetic storm (Allen et al., 1989), which ranks ahead of the 15 May 1921 event in Table 1, Yokoyama et al. (1998) showed that the equatorward boundary of the aurora determined by satellite observations of precipitating particles was $\sim 40^{\circ}$ corrected geomagnetic latitude.

\subsection{Aurora seen on the poleward horizon}

In the longitudes of the United States near $\sim \mathrm{W} 85^{\circ}$ where conditions for observing the aurora were most favorable (with the $\sim 0530$ UT maximum of the storm occurring near local midnight), the lowest magnetic latitudes of auroral observation ranged from $30^{\circ}$ in the Caribbean $\left(\sim 75^{\circ} \mathrm{W}\right.$ longitude $)$ to $33^{\circ}$ in Sinaloa, Mexico $\left(\sim 110^{\circ} \mathrm{W}\right)$. Further west, Petterson on the S.S. Hyades $\left(\sim 145^{\circ} \mathrm{W}\right)$ observed the aurora at a magnetic latitude of $35^{\circ}$. From each of these various longitudes, the aurora is reported as reaching altitudes from 40 to $50^{\circ}$ on up to the zenith (and beyond for the Hyades), so it seems certain that the aurora was visible from latitudes below $30^{\circ}$. 


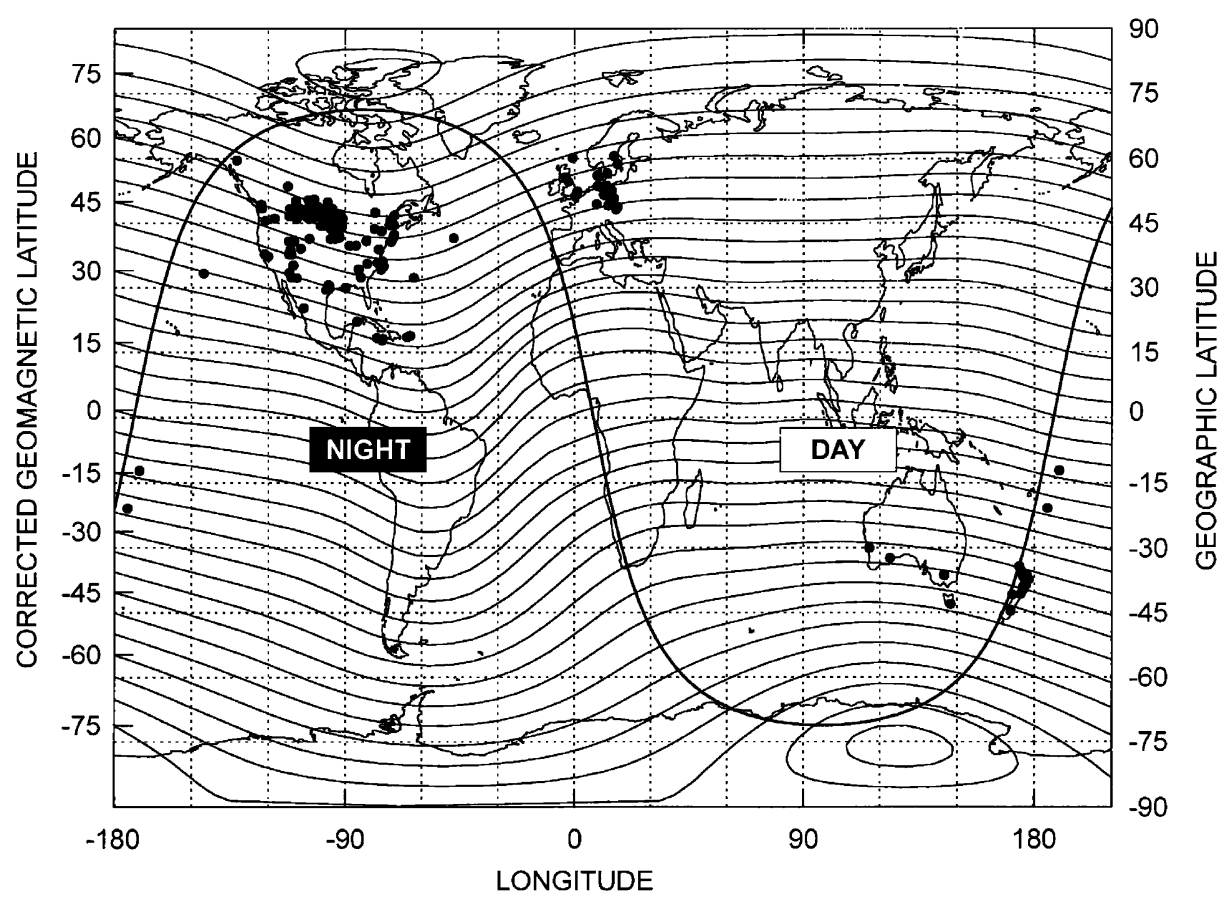

Fig. 4. Locations for which aurora were reported on 14-15 May 1921. Both geographic and corrected geomagnetic latitudes are indicated, as is the day-night terminator for 0530 UT on 15 May, at the peak of the storm.

\subsection{Observations at Apia, Samoa}

This report is puzzling because it does not fit the trend of the other observations. At $13^{\circ} \mathrm{S}$ magnetic latitude, Apia is $\sim 15^{\circ}$ equatorward of the lowest latitude reporting in North America where conditions were optimal for viewing aurora. As pointed out by Westland (1921), this would imply an impossible auroral height of $\sim 2000 \mathrm{~km}$ (assuming that the aurora was overhead at Auckland). Yet the reports themselves seem credible for a variety of reasons: (1) They are given by two professional observers; (2) the description in terms of timing (near storm maximum), location (centered on the magnetic meridian), morphology (arc with ray or "streamer"), color (red), and dynamics are detailed and in general accord with accounts of other low-latitude aurora (except for perhaps the discrete arc instead of a diffuse glow); (3) Angenheister and Westland report that aurora was observed at Tongatabu ( $10^{\circ}$ (magnetic) south of Apia), with the detail (Westland, 1921) that the aurora appeared higher in the sky at Samoa; (4) and they note that the sky was free from clouds during the observation. We are thus forced to set aside simple dismissive explanations for this observation such as moonlight reflected from clouds, for example. On the other hand, the lack of independent confirmation for this low-latitude auroral sighting in either hemisphere renders it suspect. Both Angenheister and Westland had difficulty accounting for their observation.
Was this a case of very high-altitude aurora as posed by Angenheister (1921) (also in Angenheister, 1922) or was it a situation where the observers in Samoa and those in New Zealand "were not looking at the same thing (Westland, 1921)?" Of the various possible explanations to account for the observation at Samoa given below, none is compelling:

(a) $2000 \mathrm{~km}$ high aurora. Loomis (1861) used triangulation to obtain "extraordinarily great" (Vallance Jones, 1992) peak heights of $800-850 \mathrm{~km}$ for the tropical auroras of 1859 . Loomis' calculations are based largely on diffuse red glows seen on the horizon from low latitudes, similar in color if not form to the auroral arc described by Angenheister and Westland (1921). From a review of Loomis' analysis, it appears that auroral rays occasionally reached well above the height of the diffuse glows used in his triangulations. Thus auroral emission may have occurred at heights $>800 \mathrm{~km}$ in these events, but emission at heights $\sim 2000 \mathrm{~km}$ is unlikely because of the rapid fall-off of the density of oxygen and other species with height. Moreover, Angenheister and Westland clearly described an auroral arc rather than a collection of rays.

(b) Sunlit aurora. Sunlit aurora are known to be observable at greater heights than aurora occurring near local midnight (Störmer, 1955). Angenheister and Westland (1921) comment that a "little twilight" was still apparent in the sky at Apia; the calculated sunset was 0508 UT, approximately $40 \mathrm{~min}$ before the aurora was first noted. (Observing con- 
ditions were similar at Auckland ("just after dusk") where the sun set at 0521 UT and the aurora was first noted about 0600 UT (Fig. 4).) During the related magnetic storm on the night of 13-14 May which formed part of the sequence of strong geomagnetic activity in mid-May, Störmer had observed sunlit aurora from Norway in which the highest rays were visible $\sim 800 \mathrm{~km}$ above the Earth's surface. For other storms, Störmer reported rare occurrences of sunlit aurora at maximum altitudes $\sim 1000 \mathrm{~km}$ in the polar regions. Since the activity near 0530 UT was much stronger than that observed on the night of 13-14 May, it seems plausible that sunlit aurora would have been observable at heights greater than $\sim 800 \mathrm{~km}$ for that event. As noted above, however, it is doubtful that such emission could extend to $2000 \mathrm{~km}$. Also, the great heights reported by Störmer (1955) refer to coronal rays rather than arcs.

(c) Illumination of the upper atmosphere. Finally, Burns (1921) speculated that the observers in Samoa might have been observing the "illumination of the upper atmosphere by the aurora, which was itself invisible. It must be assumed that the auroral display was of sufficient intensity to render the upper air luminous for over 1000 miles round. The curvature of the arch is caused by the curvature of the earth as the luminous stratum is at a constant height above the surface of the earth". Difficulties with this explanation include the "streamer" reported by Angenheister and Westland (1921), the location of the arc on the magnetic meridian, and the greater height of the feature as seen at Tongatapu (Westland, 1921).

\section{Conclusions and discussion}

With the exception of the report from Samoa, the available observations of the visual aurora for the 14-15 May 1921 magnetic storm show consistency in placing the maximum observed equatorward extent of the aurora at between 30 and $35^{\circ}$ magnetic latitude. Results from three widely separated meridians $\left(\sim \mathrm{W} 75^{\circ}\right.$ (Jamaica), $\sim \mathrm{W} 110^{\circ}$ (Mexico), and $\sim \mathrm{W} 145^{\circ}$ (S.S. Hyades)) in the northern hemisphere give this same lower limit of observation. The lowest magnetic latitude at which overhead (coronal) aurora was observed was $40^{\circ}$. An apparently credible report of aurora at Apia, Samoa $\left(13^{\circ} \mathrm{S}\right.$ geomagnetic latitude) during this event is puzzling. We considered various possible explanations, none convincing.

How do the confirmed overhead/equatorward limits of $40^{\circ} / 30^{\circ}$ observed for the May 1921 event compare with those observed for other historic low-latitude auroras. Loomis (1861) and Kimball (1960) assembled data for the great auroras of 28-29 August and 1-2 September 1859. From Kimball's list, we obtain corresponding overhead/equatorward values of $48^{\circ} / 32^{\circ}$ and $41^{\circ} / 20^{\circ}$, respectively, for these events. Thus, the 14-15 May 1921 event appears to rank between the two great 1859 storms in terms of its auroral extent. Such a statement, however, must necessarily be followed by a caveat on the vagaries of auroral observation (not to mention reporting) which depend critically on such factors as the timing of the storm (preferably at a time when local midnight corresponds to a well-populated developed region) and local weather conditions. For example, Loomis (1861) determined that the corona in the 1-2 September 1859 event would have reached the magnetic zenith at a magnetic latitude of $36^{\circ}$ along the east coast of the United States, considerably lower than the lowest latitude of $41^{\circ}$ at which corona was actually reported.

In his analysis of the great aurora of 25 September 1909, Silverman (1995) found that the most equatorward observations was made at a magnetic latitude of $30^{\circ}$, similar to that obtained for the 14-15 May 1921 and 28-29 August 1959 events. The 4 February 1872 aurora probably rivaled that of 1-2 September 1859 in terms of its geographic extent. In fact, aurora for this event have been reported from Bombay and Aden, both at approximately $10^{\circ}$ geomagnetic latitude. Silverman (1995) discounts these observations as likely confusion of telegraphic effects with actual auroral sightings but several other reports exist for somewhat higher geomagnetic latitudes, e.g., seven stations in India between 19 and $24^{\circ}$ geomagnetic latitude (Chapman, 1957).

\section{Acknowledgements}

One of the authors (S.M.S.) wishes to acknowledge partial support of this work under NASA grant W-21560. Thanks are also due to the many librarians in New Zealand who helped locate newspaper reports, and to Stuart Burgess of the National Institute of Water \& Atmospheric Research Ltd, Wellington, New Zealand, who searched the records of the New Zealand Meteorological Service for pertinent data. We are indebted to R.D. McKnight and Tony Hurst for providing us with the magnetic data from Apia for May 1921. We wish also to thank Rich Vondrak, who suggested the importance of searching for any concurrent auroral observation from Hawaii, somewhat north of the conjugate points for Samoa. We thank Walter Gonzalez for assisting us in the search for records from South America. We are also greatly indebted to Joe Allen and Les Harris of NOAA for providing help in finding the data.

\section{References}

Allen, J., Frank, L., Sauer H., Reiff, P., 1989. Effects of the March 1989 Solar activity. EOS Transactions of the American Geophysical Union 70 (46) 1486-1488.

Angenheister, G., 1921. Note on the magnetic storm May 13-16, 1921. Terrestrial Magnetism and Atmospheric Electricity 26, $116-119$. 
Angenheister, G., 1922. Anmerkung zur Störung vom 13. bis 16. Mai 1921. Meteorologische Zeitschrift 39, 20-23.

Angenheister, G., Westland, C.J., 1921. The magnetic storm of May 13-14, 1921: observations at Samoa Observatory. New Zealand Journal of Science and Technology 4, 201-202.

Angenheister, G., Westland, C.J., 1922. Magnetische Störung und Polarlicht vom 13. bis 16. Mai 1921 nach Beobachtungen des Samoa-Observatoriums. Meteorologische Zeitschrift 39, 19-20.

Beer, A., 1922. Die Polarlichter vom 13. Und 15. Mai 1921. Meteorologische Zeitschrift 39, 144-147.

Berger, R.A., 1921. Polarlichtbeobachtungen am 13. bis 15. Mai 1921. Meteorologische Zeitschrift 38, 309-311.

Botley, C.M., 1957. Some great tropical aurorae. Journal of British Astronomical Society 67, 188-191.

Burns, G.J., 1921. Correspondence. Journal of British Astronomical Society 31,380 .

Chapman, S., 1957. The aurora in middle and low latitudes. Nature $179,7-11$.

Chree, C., 1921. The magnetic storm of May 13-17. Nature 107, 359.

Cliver, E.W., 1995. Solar activity and geomagnetic storms: from M regions and flares to coronal holes and CMEs. Eos, Transactions of the American Geophysical Union 76 (8), 75,83.

Cook, A., 1921. Grace, [letter]. Engineering Mechanics and World of Science 113, 200-201.

Douglass, A.E., 1921. The aurora of May 14, 1921. Science 54, 14.

Feldstein, Y.I., Starkov, G.V., 1967. Dynamics of auroral belt and polar geomagnetic disturbances. Planetary Space Science 15, 209-229.

Gibbs, A., 1921. Effects of the recent aurora on telegraph-lines, telephone-lines, and wireless stations. New Zealand Journal of Science and Technology 4, 183-188.

Hartnell, G., 1921. The magnetic storm of May 13-16, 1921, at Cheltenham Observatory, Maryland. Terrestrial Magnetism and Atmospheric Electricity 26, 25.

Hazard, D.L., 1924. Results of observations made at the United States Coast and Geodetic Survey Magnetic Observatory at Cheltenham, MD., in 1921 and 1922. Government Printing Office, Washington.

Irumata, T., 1921. The magnetic storm of May 13-17, 1921, at the Meteorological Observatory of Tsingtau, China. Terrestrial Magnetism and Atmospheric Electricity 26, 112-113.

Kimball, D.S., 1960. A study of the aurora of 1859 , University of Alaska, Scientific Report No. 6, UAR-R109.
Lampland, C.O., 1921. Observations of the aurora at the Lowell Observatory May 14, 1921. Science 54, 185-187.

Lemos, A., 1921. The magnetic storms of March 22-25, 1920 and May 13-17, 1921, at Vassouras Magnetic Observatory, Brazil. Terrestrial Magnetism and Atmospheric Electricity 26, 96-98.

Lindley, J.G., 1921. The aurora seen from Sinaloa, Mexico in latitude $27^{\circ} \mathrm{N}$. Science 54, 14 .

Loomis, E., 1861. On the great Auroral Exhibition of Aug. 28th to Sept. 4th, 1859, and on Auroras generally - 8TH ARTICLE. American Journal of Science 82, 318-335.

Lyman, H., 1921. Remarkable aurora of May 14-15, 1921. Monthly Weather Review 49, 406-409.

Mayaud, P.N., 1973. A hundred year series of geomagnetic data 1868-1967. I.A.G.A. Bulletin No. 33, IUGG Publications Office.

Mayaud, P.N., 1980. Derivation, Meaning, and Use of Geomagnetic Indices. Geophysical Monographs Series, Vol. 22. AGU, Washington, DC.

Royal Greenwich Observatory, 1955. Sunspot and Geomagnetic-Storm Data, derived from Greenwich observations, 1874-1954. Her Majesty's Stationery Office, London.

Russell, H.N., 1921. Observations of the aurora at the Lowell Observatory May 14, 1921. Science 54, 183.

Silverman, S.M., 1995. Low latitude auroras: the storm of 25 September 1909. Journal of Atmospheric and Solar Terrestrial Physics 57, 673-685.

Skey, H.F., 1921. The recent magnetic storm, 14th to 17th May, 1921. New Zealand Journal of Science and Technology 4, 197201.

Slipher, V.M., 1921. Observations of the aurora at the Lowell Observatory May 14, 1921. Science 54, 184-185.

Störmer, C., 1955. The Polar Aurora. Clarendon Press, Oxford.

Vallance Jones, A., 1992. Historical review of great auroras. Canadian Journal of Physics 70, 479-487.

Westland, C.J., 1921. A note upon the Aurora Australis. Journal of British Astronomical Society 31, 380.

Westland, C.J., 1923. Magnetic Report for the Year 1921. New Zealand Government Printer, Wellington.

Whalen, J.A., O'Neil, R.R., Picard, R.H., 1985. The aurora. In: Jursa, A.S. (Ed.), Handbook of Geophysics and the Space Environment. Air Force Geophysics Laboratory Hanscom AFB, MA, pp. 12-1-12-42 (Chapter 12).

Yokoyama, N., Kamide, Y., Miyaoka, H., 1998. The size of the auroral belt during magnetic storms. Annales Geophysicae 16, 566-573. 